\title{
Exigências de triptofano e padrão de recuperação do desempenho de poedeiras comerciais após alimentação com rações deficientes em triptofano ${ }^{1}$
}

\section{Bruno José Deponti², Douglas Emygdio de Faria ${ }^{3}$, Daniel Emygdio de Faria Filho4 ${ }^{4}$ Luiz Gustavo Rombola ${ }^{5}$, Lúcio Francelino Araujo ${ }^{3}$, Otto Mack Junqueira ${ }^{6}$}

\author{
${ }^{1}$ Parte da dissertação de Mestrado do primeiro autor apresentada à FZEA/USP/Pirassununga - SP. \\ 2 Médico veterinário, mestre em Zootecnia. \\ ${ }^{3}$ Departamento de Zootecnia da FZEA/USP/Pirassununga - SP. \\ ${ }^{4}$ Departamento de Zootecnia do NCA/UFMG/Montes Claros - MG. \\ ${ }^{5}$ Zootecnista, mestre em Zootecnia. \\ ${ }^{6}$ Departamento de Zootecnia da FCAVIUNESP/Jaboticabal - SP.
}

\begin{abstract}
RESUMO - Este experimento foi conduzido para avaliar as exigências de triptofano e o padrão de recuperação do desempenho de poedeiras alimentadas com rações deficientes em triptofano. Foram utilizadas 160 poedeiras comerciais da linhagem Hisex White distribuídas em um delineamento inteiramente casualizado com cinco níveis de triptofano nas dietas $(0,13 ; 0,15 ; 0,17 ; 0,19$ e $0,21 \%)$, com oito repetições de quatro aves. As poedeiras permaneceram por duas semanas em adaptação (51 a 52 semanas), por seis semanas para avaliação da exigência de triptofano (53 a 58 semanas) e por quatro semanas para determinação do padrão de recuperação do desempenho (59 a 62 semanas). A produção e a massa de ovos foram prejudicadas quando as poedeiras foram alimentadas com rações contendo 0,13\% de triptofano, no entanto, o desempenho foi recuperado após uma semana de alimentação com ração contendo $0,21 \%$ desse aminoácido. A qualidade interna dos ovos não foi influenciada pelos níveis de triptofano estudados (ingestão de 137,1 a 228,0 mg triptofano/dia). As exigências de triptofano foram estabelecidas entre 161 e $188 \mathrm{mg} /$ dia, dependendo da característica avaliada (produção ou massa de ovos) e do modelo de regressão aplicado (polinomial, exponencial ou segmentado).
\end{abstract}

Palavras-chave: aminoácidos, avicultura, exigências nutricionais, galinhas, ovos

\section{Tryptophan requirements and recovery performance pattern of commercial laying hens after feeding tryptophan-deficient diets}

\begin{abstract}
This experiment was carried out to evaluate the tryptophan (Trp) requirements and the recovery performance pattern of laying hens fed Trp-deficient diets. One hundred sixty Hisex White commercial laying hens were randomly distributed in five Trp levels in the diets $(0.13,0.15,0.17,0.19$ and $0.21 \%$ ) with eight replicates of four birds. The laying hens remained for two weeks in adaptation (51 to 52 weeks), for six weeks for evaluation of Trp requirements (53 to 58 weeks) and for four weeks for the determination of the recovery performance pattern (59 to 62 weeks). Egg production and egg mass were impaired when laying hens were fed diets containing $0.13 \%$ of Trp, however, the performance was recovered after one week of feeding under a diet containing $0.21 \%$ of this amino acid. Internal egg quality was not influenced by the Trp levels studied (intake among 137.1 to 228.0 of Trp mg/day). Tryptophan requirements ranged from 161 to $188 \mathrm{mg} / \mathrm{ay}$, depending on the characteristics evaluated (egg production or egg mass) and the regression model applied (polynomial, exponential or broken line).
\end{abstract}

Key Words: amino acids, birds, eggs, hens, nutritional requirements

\section{Introdução}

Os níveis de proteína ou de aminoácidos em rações para aves compõem parcela significativa do custo da alimentação e são determinantes da produtividade do lote, por isso, interferem diretamente na lucratividade do empreendimento avícola. Em dietas à base de milho e soja, o primeiro aminoácido limitante para aves é a metionina, seguida pela lisina e depois pelo triptofano. No entanto, nas formulações atuais em que a metionina e a lisina são normalmente suplementadas nas suas formas sintéticas, o triptofano é o primeiro aminoácido limitante (Peganova et al., 2003).Em virtude da disponibilidade do triptofano sintético (L-Trp) no mercado de rações animais, é possível fazer a suplementação deste aminoácido nas rações para aves a preços compatíveis. No entanto, a determinação da viabi- 
lidade econômica da suplementação de triptofano sintético para poedeiras comerciais depende da geração de dados consistentes quanto à exigência desse aminoácido.

Ao longo dos anos, as exigências de triptofano modificam constantemente, principalmente em decorrência da evolução genética das linhagens comerciais. No NRC (1971), a recomendação de triptofano para poedeiras comerciais foi de $110 \mathrm{mg} /$ ave/dia, enquanto, no NRC (1994), a indicação foi de $160 \mathrm{mg} / \mathrm{ave} / \mathrm{dia}$. De acordo com Rostagno et al. (2005), poedeiras leves pesando 1.600 g necessitam de $188 \mathrm{mg} /$ ave/dia de triptofano total. São poucos os trabalhos recentes avaliando a exigência desse aminoácido para poedeiras comerciais (Russell \& Harms, 1999; Harms \& Russell, 2000; Peganova et al. 2003; Antar et al., 2004) e os resultados são bastante variáveis. Russell \& Harms (1999) e Harms \& Russell (2000) verificaram que poedeiras comerciais precisam ingerir triptofano em quantidades de 136 e 139,8 mg/ave/dia, respectivamente, para maximizar a produção de ovos. Peganova et al. (2003) encontraram exigências de triptofano de 171 a $210 \mathrm{mg} /$ ave/dia de acordo com a característica avaliada e o modelo estatístico utilizado. Em um dos experimentos conduzidos por Antar et al. (2004), os autores verificaram que poedeiras ingerindo triptofano nas quantidades de 147, 160 e $170 \mathrm{mg} /$ ave/dia apresentaram valores semelhantes de produção de ovos, no entanto, o peso dos ovos foi significativamente menor para poedeiras que ingeriram triptofano na quantidade de $147 \mathrm{mg} /$ ave/dia em comparação àquelas que ingeriram $160 \mathrm{mg} /$ ave/dia.

A indústria de processamento de ovos vem crescendo muito em todo o mundo como resultado da segurança e da praticidade de seus produtos (Faria et al., 2002a). Desse modo, é importante a determinação da qualidade interna dos ovos, pois podem apresentar alterações decorrentes dos níveis nutricionais utilizados. A porcentagem de sólidos totais éuma importante medida de qualidade interna e determina o valor comercial da gema e do albúmen líquidos; a indústria de processamento pode exigir níveis específicos de sólidos totais para ovos que serão processados, pois essa característica pode influenciar a qualidade de alimentos preparados posteriormente (Prochaska et al., 1996). No entanto, não foram encontrados trabalhos sobre níveis de triptofano e qualidade interna dos ovos de poedeiras comerciais.

É importante a determinação da seqüência e do tempo necessário para que as poedeiras alimentadas com rações deficientes em determinados nutrientes recuperem as características de produtividade prejudicadas durante o período de nutrição inadequada. Faria et al. (2002b) verificaram que poedeiras comerciais alimentadas com rações deficientes em treonina precisaram de duas a três semanas para recuperar o desempenho e concluíram que a deficiência de treonina não promoveu danos permanentes ao sistema reprodutivo das poedeiras. Em estudos sobre níveis de triptofano para poedeiras (Russell \& Harms, 1999; Harms \& Russell, 2000; Peganova et al., 2003), não se verificou o padrão de recuperação do desempenho de aves alimentadas com rações com níveis insuficientes deste aminoácido.

Este estudo foi realizado com os objetivos de determinar as exigências de triptofano com base nas características de desempenho produtivo e na qualidade interna dos ovos e avaliar o padrão de recuperação do desempenho de poedeiras leves alimentadas com baixos níveis de triptofano.

\section{Material e Métodos}

O experimento foi conduzido no Aviário Experimental da Faculdade de Medicina Veterinária e Zootecnia (FMVZ), campus da USP de Pirassununga, SP.

As aves foram mantidas alojadas por um período de 12 semanas, duas de adaptação ( $51^{\mathrm{a}}$ a $52^{\mathrm{a}}$ - semana), seis para determinação das exigências de triptofano ( $53^{\mathrm{a}}$ a $58^{\underline{a}}$ semana) e quatro para verificação do padrão de recuperação do desempenho (59a a 62a semana). Foram utilizadas 160 poedeiras comerciais da linhagem Hisex White, distribuídas em um delineamento inteiramente casualisado com cinco tratamentos $(0,13 ; 0,15 ; 0,17 ; 0,19$ e $0,21 \%$ de triptofano total na ração), cada um com oito repetições de quatro aves, totalizando 40 unidades experimentais. As rações experimentais, isoenergéticas e isonutritivas, foram formuladas à base de milho, farelo de soja e farelo de glúten de milho, com níveis de triptofano que variaram conforme a inclusão de triptofano sintético (L-Trp) (Tabela 1).

As aves foram alojadas individualmente em gaiolas de arame galvanizado medindo 0,25 $\mathrm{m} \times 0,45 \mathrm{~m} \times 0,40 \mathrm{~m}$ (frente, profundidade e altura, respectivamente) e foram providas de comedouro tipo calha e de bebedouros tipo nipple. Empregou-se manejo convencional, com ração e água à vontade e programa de luz de 17 horas por dia. As temperaturas mínima, máxima e média obtidas no galpão durante o período experimental foram 13,$8 ; 26,3$ e $20,1^{\circ} \mathrm{C}$, respectivamente.

O desempenho foi avaliado no período de 53 a 58 semanas de idade por meio dos consumos de ração (g/ave/dia), de triptofano (mg/ave/dia) e de energia metabolizável (kcal/ ave/dia), da produção (\%/ave/dia), do peso (g) e da massa de ovos (g/ave/dia) e da conversão alimentar (g/g). O consumo de ração foi obtido pela diferença entre a quantidade de ração fornecida no início e a sobra ao final do experimento. O consumo de triptofano e de energia metabolizável foram calculados pela multiplicação do consumo de ração pelo teor de triptofano e energia metabolizável 
das rações experimentais. A produção de ovos foi obtida registrando-se diariamente a postura de ovos e expressando os resultados como porcentagem do número de aves alojadas. O peso dos ovos foi medido duas vezes por semana pesando-se toda a produção de ovos e calculando-se a média. A massa de ovos foi calculada pela multiplicação da produção de ovos pelo peso dos ovos e a conversão alimentar foi obtida pela relação entre o consumo de ração e a massa de ovos.

A qualidade interna dos ovos foi determinada por meio da unidade Haugh, das porcentagens de gema e de albúmen (uma vez por semana) e do teor de sólidos totais (\%) da gema e do albúmen (final da 58모 semana). A unidade Haugh (UH) foi obtida pela fórmula proposta por Nesheim et al. (1979): $\mathrm{UH}=100 \mathrm{x} \log \left(h+7,57-1,7 p^{0,37}\right)$, em que $h$ refere-se à altura do albúmen (mm) e $p$ representa o peso do ovo (g). A altura do albúmen foi obtida a $5 \mathrm{~mm}$ da gema com auxílio de um micrômetro com precisão de $0,1 \mathrm{~mm}$. O peso dos ovos foi obtido com balança analítica de precisão. As porcentagens de gema e albúmen foram obtidas pela separação da gema e do albúmen e expressas como porcentagem do ovo fresco. Para determinação do teor de sólidos totais, utilizou-se o procedimento descrito por Prochaska et al. (1996). A gema e o albúmen de quatro ovos por parcela foram separados e homogeneizados por parcela. Amostras de $10 \mathrm{~g}$ de cada componente foram colocadas em placas de Petri e mantidas em estufa de circulação forçada a $105^{\circ} \mathrm{C}$ por 24 horas. Em seguida, foram colocadas para esfriar em dessecador e, posteriormente, pesadas e expressas como porcentagem do peso inicial (úmido).

Tabela 1 - Composição percentual das rações experimentais Table 1 - Percentage composition of the experimental diets

\begin{tabular}{|c|c|c|c|c|c|}
\hline \multirow[t]{2}{*}{$\begin{array}{l}\text { Ingrediente (\%) } \\
\text { Ingredient }\end{array}$} & \multicolumn{5}{|c|}{$\begin{array}{c}\text { Nível de triptofano (\%) } \\
\text { Tryptophan level }\end{array}$} \\
\hline & 0,13 & 0,15 & 0,17 & 0,19 & 0,21 \\
\hline Farelo de soja (Soybean meal) & 10,32 & 14,84 & 16,11 & 16,07 & 16,03 \\
\hline Farelo de glúten milho (Corn gluten meal) & 8,75 & 5,11 & 4,00 & 4,00 & 4,00 \\
\hline Óleo vegetal (Soybean oil) & - & 0,02 & 0,03 & 0,03 & 0,03 \\
\hline Sal (Salt) & 0,39 & 0,38 & 0,37 & 0,37 & 0,37 \\
\hline L-lisina (L-lysine) & 0,37 & 0,24 & 0,20 & 0,20 & 0,20 \\
\hline DL-metionina (DL-methionine) & 0,09 & 0,10 & 0,11 & 0,11 & 0,11 \\
\hline L-triptofano (L-tryptophan) & - & - & 0,014 & 0,035 & 0,057 \\
\hline L-treonina (L-threonine) & 0,038 & - & - & - & - \\
\hline L-valina (L-valine) & 0,131 & - & - & - & - \\
\hline
\end{tabular}

Composição calculada

Calculated composition

\begin{tabular}{|c|c|c|c|c|c|}
\hline EMAn (kcal/kg) (AMEn) & 2.750 & 2.750 & 2.750 & 2.750 & 2.750 \\
\hline Proteína bruta (Crude protein) & 16,0 & 16,0 & 16,0 & 16,0 & 16,0 \\
\hline $\mathrm{Ca}$ & 3,80 & 3,80 & 3,80 & 3,80 & 3,80 \\
\hline P disponível (Available P) & 0,38 & 0,38 & 0,38 & 0,38 & 0,38 \\
\hline Ácido linoléico (Linoleic acid) & 1,40 & 1,40 & 1,40 & 1,40 & 1,40 \\
\hline \multicolumn{6}{|l|}{ Aminoácidos totais (\%) (Total amino acids) } \\
\hline Lisina (Lysine) & 0,84 & 0,84 & 0,84 & 0,84 & 0,84 \\
\hline Treonina (Threonine) & 0,60 & 0,58 & 0,58 & 0,58 & 0,58 \\
\hline Valina (Valine) & 0,84 & 0,72 & 0,72 & 0,72 & 0,72 \\
\hline Isoleucina (Isoleucine) & 0,60 & 0,62 & 0,62 & 0,62 & 0,62 \\
\hline Leucina (Leucine) & 1,91 & 1,72 & 1,65 & 1,65 & 1,65 \\
\hline Arginina (Arginine) & 0,80 & 0,89 & 0,92 & 0,92 & 0,92 \\
\hline Histidina (Histidine) & 0,39 & 0,41 & 0,41 & 0,41 & 0,41 \\
\hline
\end{tabular}

${ }^{1}$ Vitaminas, minerais e aditivos por kg de ração (Vitamins, minerals and additives per $\mathrm{kg}$ of diet): vit. A - 8000 UI; vit. D3 - 2200 UI; vit. E - 20 mg; vit. K3 - 2 mg vit. B1 - $1 \mathrm{mg}$; vit B2 - 4 mg; vit. B6 - 2 mg; vit. B12 - 10 mcg; pantotenato de cálcio (calcium pantothenate) - 10 mg; niacina (niacin) - 25 mg; colina (choline) - 207,13 mg; ácido fólico (folic acid) - 0,4 mg; biotina (biotin) - 15 mcg; Se - 0,2 mg; Cu - 7,8 mg; Fe - 30 mg; Zn - 65 mg; Mn - 70 mg; I - 1 mg; antioxidante (antioxidant) BHT - $120 \mathrm{mg}$; Olaquindox 29,4 mg; Violeta genciana (Gencian violet) - 14,85 mg. 
No final da 58 $8^{\mathrm{a}}$ semana, encerrou-se o período de determinação das exigências de triptofano e iniciou-se a verificação do padrão de recuperação do desempenho das poedeiras alimentadas com baixos níveis de triptofano. As poedeiras foram mantidas nas mesmas gaiolas, sendo retiradas as rações experimentais. Em seguida, forneceu-se a ração com 0,21\% de triptofano (Tabela 1) nas 40 unidades experimentais por um período de quatro semanas. Semanalmente, foram avaliadas as características de desempenho, conforme descrito anteriormente.

Os dados foram analisados quanto à presença de dados discrepantes e, em seguida, quanto ao atendimento das pressuposições de homogeneidade de variâncias e normalidade dos erros. Depois de constatado o atendimento das pressuposições, os dados foram submetidos à análise de variância por meio do procedimento General Linear Model do programa SAS ${ }^{\circledR}$ (Littell et al., 2002) e, em caso de diferença significativa, as médias foram comparadas pelo teste Tukey (5\%). Para determinação das exigências de triptofano, foram ajustados modelos de regressão polinomial, exponencial e segmentada para as características com análise de variância significativa (Freund \& Littell, 2000).

\section{Resultados e Discussão}

Os níveis de triptofano da dieta não influenciaram de forma significativa o consumo de ração (Tabela 2), o que está de acordo com os resultados obtidos por Ohtani et al. (1989). No entanto, de modo geral, resultados na literatura indicam que o consumo de ração diminui quando administrados níveis muito baixos de triptofano. Pequisadores (Jensen et al., 1990; Russell \& Harms, 1999; Harms \& Russell, 2000; Peganova et al., 2003) verificaram diminuição no consumo de ração em poedeiras alimentadas com níveis de triptofano iguais ou inferiores a $0,13 \%$. Neste estudo, o consumo de tripotofano variou significativamente de 137,1 a 228,0 mg/ave/dia conforme aumentaram os níveis de triptofano nas rações. Portanto, a ingestão deste aminoácido em níveis de 137 mg/ave/dia não é baixa o suficiente para suprimir o consumo de ração. Como não houve alteração significativa no consumo de ração e as rações foram isoenergéticas, o consumo de energia metabolizável também não foi alterado pelas dietas experimentais.

A dieta com $0,13 \%$ de triptofano proporcionou menor produção e massa de ovos em relação àquelas com maior teor deste aminoácido. A literatura é conclusiva ao demonstrar a importância da ingestão mínima de triptofano para manter produção e massa de ovos adequados (Jensen et al., 1990; Russell \& Harms, 1999; Harms \& Russell, 2000; Peganova et al., 2003). Segundo Jensen et al. (1990), dietas contendo níveis de triptofano inferiores a $0,16 \%$ promoveram redução da produção de ovos, enquanto Russell \& Harms (1999) e Harms \& Russell (2000) encontraram menor produção e massa de ovos em poedeiras alimentadas com níveis mais baixos de $0,15 \%$ de triptofano nas rações. Nos estudos de Peganova et al. (2003), somente níveis extremamente baixos de triptofano $(0,10 \%)$ proporcionaram menor produção dos ovos. Os resultados desta pesquisa demonstraram que, para produção e massa de ovos adequados, é necessária ingestão mínima de triptofano de 165,1 mg/ave/ $\operatorname{dia}(0,15 \%)$.

O peso dos ovos não foi afetado $(\mathrm{P}<0,05)$ pelos níveis de triptofano utilizados, o que está de acordo com o observado por Ohtani et al. (1989), Jensen et al. (1990) e Russell \& Harms (1999). Contudo, Harms \& Russell (2000) notaram aumento no peso dos ovos quando elevaram o teor de triptofano na ração, embora os níveis de proteína e de outros aminoácidos como metionina e lisina também tenham sido aumentados conforme os níveis de triptofano, o que pode explicar o maior peso dos ovos.

A conversão alimentar não diferiu entre as aves alimentadas com diferentes níveis de triptofano. Ohtani et al. (1989)

Tabela 2 - Desempenho de poedeiras leves alimentadas com dietas com diferentes níveis de triptofano no período de 53 a 58 semanas de idade

Table 2 - Performance of white laying hens fed diets with different tryptophan levels in the period from 53 to 58 weeks of age

\begin{tabular}{|c|c|c|c|c|c|c|}
\hline \multirow[t]{2}{*}{ Item } & \multicolumn{5}{|c|}{$\begin{array}{l}\text { Nível de triptofano (\%) } \\
\text { Tryptophan level }\end{array}$} & \multirow[t]{2}{*}{ CV $(\%)$} \\
\hline & 0,13 & 0,15 & 0,17 & 0,19 & 0,21 & \\
\hline Consumo de ração (g/ave/dia) (Feed intake, g/bird/day) & 106,9 & 112,7 & 112,9 & 108,7 & 110,8 & 4,52 \\
\hline Consumo de triptofano (mg/ave/dia) (Tryptophan intake, $\mathrm{mg} / \mathrm{bird} / \mathrm{day}$ ) & $137,1^{\mathrm{e}}$ & $165,1^{\mathrm{d}}$ & $187,6^{\mathrm{c}}$ & $202,4^{b}$ & $228,0^{\mathrm{a}}$ & 4,40 \\
\hline Consumo de EM (kcal/ave/dia) (ME intake, kcal/bird/day) & 294,1 & 309,6 & 310,6 & 298,9 & 304,6 & 4,52 \\
\hline Produção de ovos (\%/ave/dia) (Egg production, \%/bird/day) & $83,8^{b}$ & $90,8^{\mathrm{a}}$ & $91,6^{\mathrm{a}}$ & $89,0^{\mathrm{a}}$ & $90,4^{\mathrm{a}}$ & 5,93 \\
\hline Peso dos ovos (g) (Egg weight, $g$ ) & 63,3 & 63,9 & 63,9 & 64,1 & 64,1 & 2,94 \\
\hline Massa de ovos (g/ave/dia) (Egg mass, g/bird/day) & $52,9^{b}$ & $58,0^{\mathrm{a}}$ & $58,6^{\mathrm{a}}$ & $57,1^{\mathrm{a}}$ & $57,9^{a}$ & 5,54 \\
\hline Conversão alimentar (g/g) (Feed conversion, g/g) & 2,03 & 1,94 & 1,93 & 1,91 & 1,94 & 5,19 \\
\hline
\end{tabular}

Médias seguidas de letras diferentes na linha diferem $(P<0,05)$ pelo teste Tukey.

Means followed by different letter within a row differ $(P<0.05)$ by Tukey test. 
verificaram que a conversão alimentar de aves alimentadas com rações contendo 0,15\% de triptofano piorou em relação à daquelas alimentadas com dietas contendo $0,20 \%$ de triptofano. Jensen et al. (1990), no entanto, encontraram pior conversão alimentar para aves alimentadas com rações com teor de triptofano abaixo de $0,16 \%$. Em estudos recentes, a conversão alimentar não é citada pelos autores (Russell \& Harms, 1999; Harms \& Russell, 2000; Peganova et al., 2003).

Os níveis de triptofano administrados não influencia$\operatorname{ram}(\mathrm{P}<0,05)$ a qualidade interna dos ovos. As características de qualidade interna podem ser influenciadas pela nutrição, especialmente pelos níveis de proteína e aminoácidos. Estudos demonstraram que o teor de lisina (Prochaska et al., 1996) e de metionina (Shafer et al., 1996) em rações para poedeiras influenciaram significativamente o percentual de gema e de albúmen e o teor de sólidos totais da gema e do albúmen. Não foram encontrados trabalhos envolvendo avaliação de níveis de triptofano na ração e da qualidade interna dos ovos. Os dados deste estudo sugerem que a qualidade interna dos ovos não é alterada pela ingestão de triptofano em níveis de 137,1 a 228,0 mg/ave/dia.

Conforme a resolução 005 de 1991, baseada no decreto no 99427 de 1990 do Ministério da Agricultura, Pecuária e Abastecimento (MAPA), a gema e o albúmen do ovo na forma líquida devem conter, respectivamente, no mínimo 43 e 11\% de sólidos totais. Em ambos os componentes (gema e albúmen), as especificações para sólidos totais estiveram em consonância com o que determina a resolução do MAPA.

As exigências de triptofano foram estimadas utilizando-se os modelos de regressão polinomial, exponencial e segmentada para as variáveis que apresentaram análise de variância significativa (produção e massa de ovos; Tabela 2). Nos modelos polinomial e exponencial (Tabela 4), estipulou-se como exigência o valor de triptofano necessário (mg/ ave/dia) para 90\% da resposta máxima e, pela regressão segmentada, a exigência foi determinada pelo ponto de quebra (break point) (Lamberson \& Firman, 2002).
Tanto para produção quanto para massa de ovos, os modelos exponencial e segmentado geraram $\mathrm{R}^{2}$ de 0,99 indicando melhores ajustes que o modelo polinomial, que apresentou $\mathrm{R}^{2}$ de 0 ,73. Pelas exigências de triptofano obtidas (Tabela 4), constatou-se que o modelo polinomial gerou a maior exigência, seguido pelo modelo exponencial, enquanto o modelo segmentado proporcionou menores exigências de triptofano. Estes resultados corroboram achados prévios nos quais o modelo segmentado gerou menor valor de exigência nutricional em relação ao exponencial e ao quadrático (Robbins et al., 1979; Lamberson \& Firman, 2002; Peganova et al., 2003).

Entre os modelos utilizados, cada um possui vantagens e desvantagens. O modelo de regressão segmentada é mais apropriado quando se pretende determinar proporções ideais de aminoácidos em relação à lisina (elaboração da proteína ideal; Mack et al., 1999), principalmente porque gera menores exigências de aminoácidos, o que é importante para que não se determine um perfil de proteína ideal com excessos de aminoácidos. Como desvantagem, a regressão segmentada é biologicamente inválida, pois a resposta do animal a doses crescentes do nutriente não aumenta de modo contínuo e também não cessa abruptamente (ponto de quebra) (Mack et al., 1999). Ainda considerando a proteína ideal, segundo Mack et al. (1999) e Baker et al. (2002), os modelos exponencial e quadrático são mais adequados para determinação da exigência de lisina para ser utilizada como referência no estabelecimento da proteína ideal, uma vez que esses modelos representam adequadamente as respostas aos acréscimos do nutriente em estudo (biologicamente válidos). Como desvantagem, segundo os autores, a determinação da exigência pelos modelos polinomial e exponencial fixando-se 90 ou 95\% da resposta máxima faz com que a determinação da exigência se torne subjetiva.

As exigências de triptofano encontradas neste trabalho foram superiores aos valores determinados por Russell \& Harms (1999) e Harms \& Russell (2000), de 136 e 139,8 mg/

Tabela 3 - Qualidade interna dos ovos de poedeiras leves alimentadas com diferentes níveis de triptofano no período de 53 a 58 semanas de idade

Table 3 - Internal quality of eggs of white laying hens fed diets with different tryptophan levels in the period from 53 to 58 weeks of age

\begin{tabular}{|c|c|c|c|c|c|c|}
\hline \multirow[t]{2}{*}{ Item } & \multicolumn{5}{|c|}{$\begin{array}{c}\text { Nível de triptofano (\%) } \\
\text { Tryptophan level }\end{array}$} & \multirow[t]{2}{*}{ CV $(\%)$} \\
\hline & 0,13 & 0,15 & 0,17 & 0,19 & 0,21 & \\
\hline Unidade Haugh (Haugh unit) & 84,8 & 85,9 & 84,5 & 84,7 & 86,3 & 3,33 \\
\hline Porcentagem de gema (\%) (Yolk percentage) & 27,0 & 27,1 & 26,8 & 27,4 & 27,2 & 2,91 \\
\hline Porcentagem de albúmen (\%) (Albumen percentage) & 58,4 & 57,6 & 58,0 & 58,0 & 58,0 & 1,78 \\
\hline Sólidos totais na gema (\%) (Yolk total solids) & 50,5 & 51,0 & 50,7 & 50,6 & 50,9 & 0,37 \\
\hline Sólidos totais no albúmen (\%) (Albumen total solids) & 11,0 & 11,0 & 10,9 & 11,0 & 11,2 & 2,71 \\
\hline
\end{tabular}

Médias seguidas de letras diferentes na linha diferem $(P<0,05)$ pelo teste Tukey.

Means followed by different letter in the same row differ $(P<0.05)$ by Tukey test. 
Tabela 4 - Modelos de regressão para determinação das exigências de triptofano com base na produção (PRO) e na massa de ovos (MO) de poedeiras leves alimentadas com dietas com diferentes níveis de triptofano

Table 4 - Regression models for determination of the tryptophan requirements based on egg production (EP) and egg mass (EM) of white laying hens fed diets with different tryptophan levels

\begin{tabular}{|c|c|c|}
\hline $\begin{array}{l}\text { Modelo de regressão } \\
\text { Regression model }\end{array}$ & $\begin{array}{c}\text { Produção de ovos (\%) } \\
\text { Egg production }\end{array}$ & $\begin{array}{c}\text { Massa de ovos (g/ave/dia) } \\
\text { Egg mass (g/bird/day) }\end{array}$ \\
\hline \multicolumn{3}{|l|}{ Polinomial (Polynomial) } \\
\hline $\begin{array}{l}\text { Segmentada (Broken line) } \\
\text { Equação (Equation) }\end{array}$ & $\operatorname{PRO}(E P)=91,27+0,371(\operatorname{Trp}-161,0)$ & $\begin{array}{l}\text { MO }(E M)=58,06+0,250 \\
(\operatorname{Trp}-160,5)\end{array}$ \\
\hline
\end{tabular}

ave/dia, respectivamente, para maximização da produção de ovos. Peganova et al. (2003) encontraram exigências de triptofano que variaram de 171 a $210 \mathrm{mg}$ /ave/dia, ligeiramente superiores à faixa de exigência determinada nesta pesquisa, de 161 a 188 mg/ave/dia. Rostagno et al. (2005) sugeriram para poedeiras leves pesando 1.600 g ingestão diária de $188 \mathrm{mg}$ /ave/dia de triptofano total, valor próximo ao encontrado quando se utilizou o modelo polinomial.

A recuperação do desempenho foi avaliada para a produção e a massa de ovos (Tabela 5), pois essas variáveis foram significativamente prejudicadas nas poedeiras alimentadas no período de 53 a 58 semanas com o nível de 0,13\% de Trp na ração (Tabela 2). Observou-se, para ambas as características, que um período de uma semana de alimentação com ração contendo $0,21 \%$ de Trp foi suficiente para a recuperação da produção e da massa dos ovos. Assim, a alimentação com rações deficientes em Trp não causa dano permanente ao sistema reprodutivo da fêmea recupera sua produtividade em curto período de tempo.

Os trabalhos para avaliação de níveis de triptofano para poedeiras comerciais não incluíram o padrão de recuperação do desempenho das poedeiras após a alimentação com ração com níveis insuficientes de triptofano (Ohtani et al., 1989; Jensen et al., 1990; Russell \& Harms, 1999; Harms \& Russell, 2000; Peganova et al., 2003). Faria et al. (2002b) estudaram a seqüência e o tempo necessário para recuperação do desempenho de poedeiras alimentadas durante oito semanas com rações com níveis insuficientes de treonina. A seqüência e o tempo de recuperação das características de desempenho, segundo esses autores, foram: consumos de ração e de energia (duas semanas); produção,
Tabela 5 - Produção e massa de ovos na 58 ${ }^{a}$ semana de idade de poedeiras leves alimentadas com dietas contendo 0,$13 ; 0,15 ; 0,17 ; 0,19$ e $0,21 \%$ de triptofano e após período de recuperação (59a a $62 \underline{a}$ semanas de idade) com dietas com $0,21 \%$ de triptofano

Table 5 - Egg production and egg mass of white laying hens fed with diets with $0.13,0.15,0.17,0.19$ and $0.21 \%$ of tryptophan and after a recovery period (59 to 62 weeks) fed diets with $0.21 \%$ of tryptophan

\begin{tabular}{|c|c|c|c|c|c|}
\hline \multirow[t]{2}{*}{$\begin{array}{l}\text { Triptofano (\%) } \\
\text { Tryptophan }\end{array}$} & \multirow[t]{2}{*}{$\begin{array}{l}58^{\mathrm{a}} \mathrm{sem} \\
58 \mathrm{wk}\end{array}$} & \multicolumn{4}{|c|}{$\begin{array}{c}\text { Período de recuperação (semana) } \\
\text { Recovery period (week) }\end{array}$} \\
\hline & & 59 & 60 & 61 & 62 \\
\hline & & \multicolumn{4}{|c|}{$\begin{array}{c}\text { Produção de ovos (\% ovos/ave/dia) } \\
\text { Egg production (\% eggs/bird/day) }\end{array}$} \\
\hline 0,13 & $87,7^{b}$ & 81,7 & 83,0 & 86,1 & 87,5 \\
\hline 0,15 & $88,3^{\mathrm{a}}$ & 84,4 & 85,3 & 83,0 & 92,0 \\
\hline 0,17 & $87,5^{\mathrm{a}}$ & 84,4 & 83,9 & 83,0 & 89,7 \\
\hline 0,19 & $87,9^{a}$ & 82,1 & 85,7 & 85,4 & 90,2 \\
\hline 0,21 & $88,8^{\mathrm{a}}$ & 87,5 & 88,8 & 85,3 & 91,1 \\
\hline \multirow[t]{2}{*}{ CV (\%) } & 9,84 & 8,94 & 11,03 & 9,87 & 8,58 \\
\hline & & \multicolumn{4}{|c|}{$\begin{array}{l}\text { Massa de ovos (g/ave/dia) } \\
\text { Egg mass (g/bird/day) }\end{array}$} \\
\hline 0,13 & $51,8^{\mathrm{b}}$ & 51,6 & 53,7 & 54,7 & 55,1 \\
\hline 0,15 & $56,4^{\mathrm{a}}$ & 54,4 & 55,1 & 53,7 & 58,9 \\
\hline 0,17 & $55,8^{\mathrm{a}}$ & 54,9 & 53,6 & 53,9 & 57,9 \\
\hline 0,19 & $57,0^{\mathrm{a}}$ & 54,4 & 55,2 & 51,3 & 58,0 \\
\hline 0,21 & $57,5^{\mathrm{a}}$ & 56,1 & 57,6 & 55,3 & 58,7 \\
\hline CV (\%) & 10,51 & 8,62 & 10,70 & 9,79 & 9,37 \\
\hline
\end{tabular}

Médias seguidas de letras diferentes na coluna diferem $(P<0,05)$ pelo teste Tukey.

Means followed by different letter in the column differ $(P<0.05)$ by Tukey test.

peso do ovo e massa (três semanas) de ovos; e peso corporal (quatro semanas). Os resultados obtidos nesta pesquisa indicaram que, em aves alimentadas com rações deficientes em triptofano, a recuperação do desempenho foi 
mais rápida (uma semana) que em situações de deficiência de treonina (Faria et al., 2002 b).

\section{Conclusões}

A produção e a massa de ovos são negativamente afetadas quando poedeiras são alimentadas durante seis semanas com rações contendo $0,13 \%$ de triptofano. O desempenho é recuperado após uma semana de alimentação com ração contendo 0,21\% de triptofano. A qualidade interna do ovo não é influenciada pelos níveis de triptofano da ração (ingestão de 137,1 a 228,0 mg/ave/dia). As exigências de triptofano se encontram na faixa de 161 a $188 \mathrm{mg} /$ ave/ dia, dependendo da característica avaliada (produção ou massa de ovos) e do modelo de regressão aplicado na análise dos dados (quadrático, exponencial ou segmentada).

\section{Literatura Citada}

ANTAR, R.S.; HARMS, R.H.; SHIVAZAD, M. et al. Performance of commercial laying hens when six percent corn oil is added to the diet at various ages and with different levels od tryptophan and protein. Poultry Science, v.83, p.447-455, 2004.

BAKER, D.H.; BATAL, A.B.; PARR, N.R. et al. Ideal ratio (relative to lysine) of tryptophan, threonine, isoleucine and valine for chicks during the second and third weeks posthatch. Poultry Science, v.81, p.485-494, 2002.

FARIA, D.E.; FARIA FILHO, D.E.; RIZZO, M.F. Interação nutrição e qualidade de ovos para processamento industrial. In: SIMPÓSIO SOBRE MANEJO E NUTRIÇÃO DE AVES E SUÍNOS, 2002, Campinas. Anais... Campinas: Colégio Brasileiro de Nutrição Animal, 2002. p.85-91a.

FARIA, D.E.; HARMS, R.H.; RUSSELL, G.B. Layer performance recovery after feeding amino acid-deficient diets. Brazilian Journal of Poultry Science, v.4, p.141-148, 2002b.

FREUND, R.J.; LITTELL, R.C. SAS ${ }^{\circledR}$ system for regression. 4.ed. Cary: 2000. (CD-ROM).

HARMS, R.H.; RUSSEL, G.B. Evaluation of tryptophan requirement of the commercial layer by using a corn-soybean meal basal diet. Poultry Science, v.79, p.740-742, 2000.
JENSEN, L.S.; CALDERON, V.M.; MENDONÇA JR., C.X. Response to tryptophan of laying hens fed practical diets varying in protein concentration. Poultry Science, v.69, p.1956-1965, 1990.

LAMBERSON, W.R.; FIRMAN, J.D. A comparison of quadratic versus segmented regression procedures for estimating nutrient requirements. Poultry Science, v.81, p.481-484, 2002.

LITTELL, R.C.; STROUP, W.W.; FREUND, R.J. SAS for linear models. 4.ed. Cary: SAS Institute, 2002. 633p.

MACK, S.; BERCOVICI, D.; GROOTE, G. et al. Ideal amino acid profile and dietary lysine specification for broiler chickens of 20 to 40 days of age. British Poultry Science, v.40, p.257265, 1999.

NATIONAL RESEARCH COUNCIL - NRC. Nutrient requirements of poultry. 7.ed. Washington, D.C.: National Academy Press, 1971. 54p.

NATIONAL RESEARCH COUNCIL - NRC. Nutrient requirements of poultry. 9.ed. Washington, D.C.: National Academy Press, 1994. 155p.

NESHEIM, M.C.; AUSTIC, R.E.; CARD, L.E. Poultry production. 12.ed. Philadelphia: Lea \& Febiger, 1979. 325p.

OHTANI, H.; SAITOH, S.; OHKAWARA, H. et al. Production performance of laying hens fed L-tryptophan. Poultry Science, v.68, p.323-326, 1989.

PEGANOVA, S.; HIRCHE, F.; EDER, K. Requirement of tryptophan in relation to the supply of large neutral amino acids in laying hens. Poultry Science, v.82, p.815-822, 2003.

PROCHASKA, J.F.; CAREY, J.B.; SHAFER, D.J. The effect of L-lysine on egg component yield and composition in laying hens. Poultry Science, v.75, p.1268-1277, 1996.

ROBBINS, K.R.; NORTON, H.W.; BAKER, D.H. Estimation of nutrient requirements from growth data. Journal of Nutrition, v.109, p.1710-1714, 1979.

ROSTAGNO, H.S.; ALBINO, L.F.T.; DONZELE, J.L. et al. Tabelas brasileiras para aves e suínos: composição de alimentos e exigências nutricionais. 2.ed. Viçosa, MG: Universidade Federal de Viçosa, 2005.

RUSSEL, G.B.; HARMS, R.H. Tryptophan requirement of the commercial hen. Poultry Science, v.78, p.1283-1285, 1999.

SHAFER, D.J.; CAREY, J.B.; PROCHASKA, J.F. Effect of dietary methionine intake on egg component yield and composition. Poultry Science, v.75, p.1080-1085, 1996. 